\title{
Pollen-mediated gene flow from transgenic safflower (Carthamus tinctorius L.) intended for plant molecular farming to conventional safflower
}

\author{
Marc A. MCPHerson ${ }^{1}$, Allen G. GOOD ${ }^{2}$, A. Keith C. TOPINKA ${ }^{1}$, Rong-Cai YANG ${ }^{1,3}$, Ross H. McKenzie ${ }^{4}$, \\ R. Jason CATHCART ${ }^{3}$, Jed A. Christianson ${ }^{5}$, Curtis StrobeCK ${ }^{2}$ and Linda M. HALL ${ }^{1,3 *}$ \\ 1 University of Alberta, Department of Agricultural, Food and Nutritional Science, 410 Ag/Forestry Building, Edmonton, Alberta, T6G 2P5, \\ Canada \\ 2 University of Alberta, Department of Biological Sciences, Z-1012 Biological Sciences Building, Edmonton, Alberta, T6G 2E9, Canada \\ 3 Alberta Agriculture and Rural Development, J.G. O’Donoghue Bldg, 7000 - 113 St. Edmonton, Alberta, T6H 5T6, Canada \\ 4 Alberta Agriculture and Rural Development, A252 Agriculture Centre, 100, 545401 - 1 Avenue S. Lethbridge, Alberta, T1J 4V6, Canada \\ 5 CSIRO Plant Industry, Black Mountain, Australia
}

Field experiments were conducted in Chile and western Canada to measure short-distance (0 to $100 \mathrm{~m})$ outcrossing from transgenic safflower (Carthamus tinctorius L.) intended for plant molecular farming to nontransgenic commodity safflower of the same variety. The transgenic safflower used as the pollen source was transformed with a construct for seed-specific expression of a high-value protein and constitutive expression of a gene conferring resistance to the broad-spectrum herbicide glufosinate. Progeny of non-transgenic plants grown in plots adjacent to the transgenic pollen source were screened for glufosinate resistance to measure outcrossing frequency. Outcrossing frequency differed among locations: values closest to the transgenic pollen source $(0$ to $3 \mathrm{~m}$ ) ranged from 0.48 to $1.67 \%$ and rapidly declined to between 0.0024 to $0.03 \%$ at distances of 50 to $100 \mathrm{~m}$. At each location, outcrossing frequency was spatially heterogeneous, indicating insects or wind moved pollen asymmetrically. A power analysis assuming a binomial distribution and a range of alpha values (type 1 error) was conducted to estimate an upper and lower confidence interval for the probable transgenic seed frequency in each sample. This facilitated interpretation when large numbers of seeds were screened from the outcrossing experiments and no transgenic seeds were found. This study should aid regulators and the plant molecular farming industry in developing confinement strategies to mitigate pollen mediated gene flow from transgenic to non-transgenic safflower.

Keywords: outcrossing / safflower / plant molecular farming / gene-flow patterns / binomial distribution / power analysis / vicinism

\section{INTRODUCTION}

Safflower is grown for its seed oil throughout the Mediterranean, Europe and in the Americas, including the US and Chile. In the Canadian prairies, safflower is a minor crop grown for a small niche bird feed market with production limited to 320 to 810 ha annually (Muendel et al., 2004). Recently, safflower (Carthamus tinctorius L.; cv. 'Centennial') was transformed for plant molecular farming (PMF) using a construct encoding a seedtargeted high-value protein and constitutive expressed phosphinothricin acetyltransferase (pat) to confer resistance to the broad-spectrum herbicide glufosinate (Lphosphinothricin). One concern with this new technology

* Corresponding author: linda.hall@ualberta.ca is pollen-mediated gene flow from transgenic to commodity safflower. The consequences of adventitious presence in commodity crops can be serious, including halting the development of a PMF crop. For example, pollen movement from a small experiment of transgenic corn expressing a gene for a pig vaccine intended for PMF being developed by ProdiGene Inc. resulted in crossfertilization of a field of corn intended for food/feed in Iowa. The neighboring fields of $63 \mathrm{ha}$. of corn growing near the site were destroyed by USA government regulators (Ellstrand, 2003).

Crop species and varieties have different rates of outcrossing that are controlled genetically and influenced by the environment (for example see Beckie et al., 2003; Eastham and Sweet, 2002; Fritz and Lukaszewski, 
1989; Hanson et al., 2005). Outcrossing for both windpollinated and insect-pollinated species decreases rapidly with distance from the pollen source with the nearest neighbors receiving most of the pollen (Levin and Kerster, 1974). Various factors affect outcrossing among plant populations: pollinator effects including pollinator species and distance to other pollen sources; spatial and abiotic factors including distance to compatible crops, humidity, wind direction and velocity, geographic and vegetative barriers; crop species effects including the number and diversity of plant species attractive to pollinators in the area, ploidy level of the populations, shape, size and density of pollen donor and receptor plant populations, floral synchrony, floral and inflorescence position on the plant, pollen longevity, and cross-compatibility. Many of these factors interact, making predictions difficult without empirical measurements (Hoyle et al., 2007; Luna et al., 2001; Messeguer, 2003; Rognli et al., 2000). While complete confinement of pollen and seed is not possible for any crop species to date (Levin and Kerster, 1974), management that incorporates spatial, temporal or vegetative barriers could minimize pollen-mediated gene flow between crops.

Safflower genotype, floral morphology and development influence the rate of self-pollination. Claassen (1950) reported a wide range of self-pollination rates for different safflower varieties (genotypes), between 9.3 and $81.5 \%$. Bees have been observed combing pollen from the stigmatic hairs of safflower in the early morning, which facilitates pollen reaching the stigma and encourages plant-to-plant movement of pollen (Howard et al., 1915). However, pollen delivered by an insect must outcompete the floret's own pollen to result in outcrossing.

Studies conducted in India using orange or red corolla (dominant trait) safflower types as the pollen donor and white (recessive trait) types as the pollen recipient demonstrated that safflower outcrossing decreases rapidly over relatively short distances (1 to $50 \mathrm{~m}$ ) (Deokar and Patil, 1976; Howard et al., 1915; Kadam and Patankar, 1942). Safflower varieties examined in these studies differed greatly in outcrossing. In close proximity, crosspollination ranged from 10 to $27 \%$ in high outcrossing varieties (Howard et al., 1915; Kadam and Patankar, 1942) and 0.08 to $1.29 \%$ for low outcrossing varieties (Deokar and Patil, 1976).

The only study of safflower outcrossing conducted in the USA also used corolla color as a marker (Claassen, 1950). Using insect exclusion cages over safflower plants, they showed that wind and mechanical collisions among flowers did not move pollen beyond $1.2 \mathrm{~m}$, suggesting that safflower pollen is not transferred extensively without insects. Outcrossing frequencies for different cultivated varieties grown in close proximity without insect exclusion ranged from 0 to $100 \%$, with most between
0.5 to $40 \%$, while higher oil-yielding safflower lines had outcrossing rates from 1 to $5 \%$. The outcrossing rate of transgenic 'Centennial' safflower, the variety developed in the USA with high seed oil content intended for PMF in the Americas, was unknown. It readily produces seeds under greenhouse conditions when insects are excluded, suggesting it is highly self-pollinating.

This study quantified the frequency of outcrossing from transgenic safflower to non-transgenic safflower under field conditions in three different environments at El Bosque (Santiago, Chile) in 2002, Westwold (British Columbia, Canada) in 2002 and Lethbridge (Alberta, Canada) in 2004. Transgenic and non-transgenic safflower (cv. 'Centennial') were used as pollen source and recipient, respectively. Outcrossing from transgenic to non-transgenic safflower produced a hemizygous seed resistant to the herbicide glufosinate. Seed harvested from the non-transgenic plants at various distances and directions from the transgenic pollen source were grown in subsequent years and the seedlings screened for glufosinate resistance. Surviving and dead plants were counted and the presence of the transgene confirmed at the protein and DNA level using molecular techniques. Pollen movement as a function of distance was modeled using regression analysis. Heterogeneity of outcrossing by direction was assessed with a log-likelihood ratio test. To draw conclusions about samples that did not contain a transgenic seed, we conducted a power analysis using a binomial distribution to determine the minimum number of seeds (sample size) from outcrossing experiments to be screened to detect at least one or more transgenic seeds at different theoretical outcrossing frequencies and confidence thresholds.

\section{RESULTS}

Seeds harvested from non-transgenic recipient plots at different directions and distances from the transgenic pollen source were screened in the field with two applications of glufosinate; survivors were considered a product of outcrossing. The frequency of outcrossing was calculated as a proportion of the number of safflower seedlings surviving glufosinate and the total number that emerged (Tabs. 1 to 3). Of the 1258 herbicide-resistant seedlings observed in the field, 302 were from El Bosque, 902 from Westwold and 54 from Lethbridge (Tabs. 1 to 3). PCR analyses of DNA extracted from 539 survivor leaf samples confirmed they all contained the transgene, pat; immunochromatography of 99 leaf samples from survivors confirmed they all contained the transgenic protein, PAT.

Outcrossing frequency at increasing distances from the pollen source was modeled using an exponential decay function. Parameter estimates for intercept $(a)$ 
Gene flow from transgenic to conventional safflower

Table 1. Harvest distances and field screening results for the outcrossing experiment at El Bosque, Santiago, Chile.

\begin{tabular}{|c|c|c|c|c|c|}
\hline \multirow{2}{*}{$\begin{array}{l}\text { Mean distance } \\
(\mathrm{m})^{1}\end{array}$} & \multirow{2}{*}{$\begin{array}{c}\text { Emergence }^{2} \\
\text { total }\left(n_{o}\right)\end{array}$} & \multirow{2}{*}{$\begin{array}{c}\text { Survivors } \\
\text { total }\end{array}$} & \multirow{2}{*}{$\begin{array}{c}\text { Outcrossing } \\
(\%)\end{array}$} & \multicolumn{2}{|c|}{$95 \%$ confidence interval $^{3}$} \\
\hline & & & & Lower & Upper \\
\hline 0.7 & 18504 & 89 & 0.48098 & 0.38760 & 0.59433 \\
\hline 2.1 & 18404 & 27 & 0.14671 & 0.09643 & 0.21377 \\
\hline 3.4 & 21156 & 22 & 0.10399 & 0.06501 & 0.15755 \\
\hline 4.6 & 21100 & 21 & 0.09953 & 0.06146 & 0.15215 \\
\hline 5.8 & 22648 & 28 & 0.12363 & 0.08201 & 0.17891 \\
\hline 7.0 & 20660 & 7 & 0.03388 & 0.01361 & 0.06967 \\
\hline 8.2 & 20728 & 20 & 0.09649 & 0.05885 & 0.14885 \\
\hline 9.4 & 17284 & 8 & 0.04628 & 0.01995 & 0.09108 \\
\hline \multicolumn{6}{|c|}{ Unharvested $(1 \mathrm{~m})^{4}$} \\
\hline 11.6 & 22116 & 22 & 0.09947 & 0.06219 & 0.15072 \\
\hline 12.8 & 23844 & 4 & 0.01677 & 0.00457 & 0.04298 \\
\hline \multicolumn{6}{|l|}{ Unharvested $(2 \mathrm{~m})^{4}$} \\
\hline 16.0 & 17912 & 10 & 0.05580 & 0.02672 & 0.10251 \\
\hline 17.2 & 15864 & 9 & 0.05673 & 0.02591 & 0.10774 \\
\hline \multicolumn{6}{|l|}{ Unharvested $(3 \mathrm{~m})^{4}$} \\
\hline 21.4 & 17792 & 20 & 0.11241 & 0.06857 & 0.17340 \\
\hline 22.6 & 18840 & 0 & 0.00000 & 0.00000 & 0.02326 \\
\hline \multicolumn{6}{|l|}{ Unharvested $(4 \mathrm{~m})^{4}$} \\
\hline 27.8 & 18408 & 10 & 0.05432 & 0.02600 & 0.09975 \\
\hline 29.0 & 15260 & 2 & 0.01311 & 0.00159 & 0.04736 \\
\hline \multicolumn{6}{|l|}{ Corner samples ${ }^{4}$} \\
\hline 52.1 & 5632 & 1 & 0.01775 & 0.00045 & 0.13089 \\
\hline 60.5 & 6648 & 2 & 0.03008 & 0.00364 & 0.10867 \\
\hline Total & 322800 & 302 & - & - & - \\
\hline Mean & 17933 & 17 & - & - & - \\
\hline
\end{tabular}

\footnotetext{
${ }^{1}$ Mean distance was used in all analyses. The corner samples were harvested from the most distant corners of the rectangular-shaped experiment (Fig. 2).

${ }^{2}$ The mean and total number of plants that emerged during the field screening with glufosinate for each distance sampled. Seed from three plots in block 8 were not screened ( 808 at $13.2 \mathrm{~m}, 812$ at $23.0 \mathrm{~m}$ and 816 at $36.8 \mathrm{~m}$ from the source plot).

${ }^{3}$ The $95 \%$ confidence interval using a relationship between $\mathrm{F}$ and binomial distributions, with a correction for the lower interval value when the number of survivors was zero as outlined in Zar (1999), p. 528.

${ }^{4}$ To reduce the amount of transgenic material to be transported back to Canada for screening, harvested material in the area between some samples was not retained.
}

and the rate of decline of outcrossing $(b)$ were significant $(P<0.0001)$, indicating that the model was not over-parameterized. The rate of decline $(b)$ was steepest (largest) at Lethbridge (Tabs. 1 to 4). The distance at which outcrossing frequency was reduced by $50 \%\left(\mathrm{O}_{50}\right)$ ranged from 6.2 to $11.4 \mathrm{~m}$; values for $\mathrm{O}_{95}$ ranged from 26.6 to $49.4 \mathrm{~m}$ (Tab. 4). The frequency of outcrossing was highest in the recipient plants closest to the source, $0.48 \%$ at $0.7 \mathrm{~m}$ in Chile, $1.67 \%$ at $3 \mathrm{~m}$ at Westwold, and $0.62 \%$ at $0.3 \mathrm{~m}$ at Lethbridge (Tabs. 1, 2 and 3, respectively). Over all three experiments, the outcrossing frequency ranged from 0.0 to $0.86 \%$ at $10 \mathrm{~m}$ and from 0.0 to $0.54 \%$ at $20 \mathrm{~m}$ from the transgenic pollen source. At distances of 50 to $100 \mathrm{~m}$ from the transgenic pollen source, the outcrossing frequency ranged from 0.0024 to $0.12 \%$ (Tabs. 1 to 3 ). In all experiments, safflower density was consistent with producer fields in similar environments and did not differ significantly between transgenic source and nontransgenic sink populations.

Several of the blocks at each location were significantly heterogeneous, as determined from the maximumlikelihood ratio test (Tab. 5), suggesting wind direction or spatial aggregation of insect pollinators played a significant role in the pattern of safflower outcrossing. Bi-weekly observations at each site indicated that flowering of the transgenic pollen source plants and the non-transgenic recipient plants was synchronous and uniform at each site. Thus, it is unlikely that flowering time or flower density influenced outcrossing rates.

No field survivors were detected from all of the blocks at a mean distance of 22.6 and $300 \mathrm{~m}$ from the source at Chile and Westwold, respectively (Tabs. 1 and 2). At Lethbridge, survivors were not detected from any blocks at several distances from the source (Tab. 3). For samples 
M.A. McPherson et al.

Table 2. Harvest distances and field screening results for the outcrossing experiment at Westwold, BC, Canada.

\begin{tabular}{|c|c|c|c|c|c|}
\hline \multirow{2}{*}{$\begin{array}{l}\text { Mean distance } \\
(\mathrm{m})^{1} \\
\end{array}$} & \multirow{2}{*}{$\begin{array}{c}\text { Emergence }^{2} \\
\text { total }\left(n_{o}\right)\end{array}$} & \multirow{2}{*}{$\begin{array}{c}\text { Survivors } \\
\text { total }\end{array}$} & \multirow{2}{*}{$\begin{array}{c}\text { Outcrossing } \\
(\%)\end{array}$} & \multicolumn{2}{|c|}{$95 \%$ confidence interval $^{3}$} \\
\hline & & & & Lower & Upper \\
\hline 3.0 & 12514 & 209 & 1.67011 & 1.44739 & 1.93467 \\
\hline 6.0 & 9707 & 154 & 1.58654 & 1.34945 & 1.87555 \\
\hline 9.0 & 10081 & 87 & 0.86301 & 0.69374 & 1.08351 \\
\hline 12.0 & 11215 & 106 & 0.94517 & 0.77346 & 1.16426 \\
\hline 15.0 & 10274 & 69 & 0.67159 & 0.49719 & 0.85012 \\
\hline 18.0 & 8663 & 47 & 0.54252 & 0.39885 & 0.72119 \\
\hline 21.0 & 8081 & 21 & 0.25987 & 0.14647 & 0.38827 \\
\hline 24.0 & 12157 & 33 & 0.27145 & 0.18658 & 0.38162 \\
\hline 27.0 & 16606 & 17 & 0.10237 & 0.05961 & 0.16422 \\
\hline 30.0 & 14396 & 15 & 0.10420 & 0.05823 & 0.17238 \\
\hline 33.0 & 11081 & 10 & 0.09025 & 0.04320 & 0.16566 \\
\hline 36.0 & 5989 & 4 & 0.06679 & 0.01820 & 0.17096 \\
\hline 39.0 & 6093 & 10 & 0.16413 & 0.07858 & 0.30109 \\
\hline 42.0 & 10155 & 11 & 0.10832 & 0.05419 & 0.19364 \\
\hline 45.0 & 8766 & 13 & 0.14830 & 0.07893 & 0.25367 \\
\hline 48.0 & 4376 & 1 & 0.02285 & 0.00058 & 0.12737 \\
\hline 51.0 & 7455 & 3 & 0.04024 & 0.00830 & 0.11742 \\
\hline 54.0 & 13306 & 16 & 0.12025 & 0.06859 & 0.19584 \\
\hline 57.0 & 14978 & 6 & 0.04006 & 0.01473 & 0.08735 \\
\hline 60.0 & 11155 & 11 & 0.09861 & 0.00049 & 0.17628 \\
\hline 63.0 & 8796 & 9 & 0.10232 & 0.04674 & 0.19423 \\
\hline 66.0 & 11499 & 8 & 0.06957 & 0.03000 & 0.13688 \\
\hline 69.0 & 12738 & 6 & 0.04710 & 0.01732 & 0.10270 \\
\hline 72.0 & 15441 & 9 & 0.05829 & 0.02662 & 0.11068 \\
\hline 75.0 & 18084 & 3 & 0.01659 & 0.00342 & 0.04842 \\
\hline 78.0 & 16457 & 5 & 0.03038 & 0.00987 & 0.07070 \\
\hline 81.0 & 20444 & 4 & 0.01956 & 0.00533 & 0.05012 \\
\hline 84.0 & 19354 & 6 & 0.03100 & 0.01140 & 0.06761 \\
\hline 87.0 & 19936 & 6 & 0.03010 & 0.01107 & 0.06564 \\
\hline 91.78 & 20265 & 1 & 0.00493 & 0.00012 & 0.02753 \\
\hline 101.0 & 18711 & 2 & 0.01069 & 0.00129 & 0.03863 \\
\hline Total & 388770 & 902 & - & - & - \\
\hline Mean & 12541 & 29 & - & - & - \\
\hline $300.00^{4}$ & 85239 & 0 & 0.00000 & 0.00000 & 0.00514 \\
\hline
\end{tabular}

${ }^{1}$ Mean distance was used in all analyses.

${ }^{2}$ The total and mean number of plants that emerged during the field screening with glufosinate for each distance sampled. Seed from three samples in blocks 2 and 3 were not screened (mean distance from the source of $45 \mathrm{~m}$ ). Data for samples collected from the distance closest to the source (mean distance from the source $0.75 \mathrm{~m}$ ) were excluded due to admixture during harvest.

${ }^{3}$ The $95 \%$ confidence interval using a relationship between $\mathrm{F}$ and binomial distributions, with a correction for the lower interval value when the number of survivors was zero as outlined in Zar (1999), p. 528.

${ }^{4}$ The single non-transgenic plot grown $300 \mathrm{~m}$ from the pollen source. These data were not included in the regression analysis but were screened in the field and are thus treated separately here.

where no transgenic seedlings were found, we employed binomial probabilities and sample sizes to conduct a power analysis to estimate the minimum detectable differences or limits of detection (Tab. 6).

Outcrossing was detected at all distances at the Chilean site except from the 18840 seeds screened from samples taken at a mean distance of $22.6 \mathrm{~m}$ in eight directions from the transgenic pollen source (Tab. 1). From the power analysis results (Tab. 6), we would accept the null hypothesis that the frequency of transgenic seeds screened from this sample was equal to or greater than 0.00025 only $1 \%$ of the time. Thus, it is likely that the frequency of transgenic seeds in this sample is less than 0.00025 . 
Gene flow from transgenic to conventional safflower

Table 3. Harvest distances and field screening results for the outcrossing experiment at Lethbridge, AB, Canada.

\begin{tabular}{|c|c|c|c|c|c|}
\hline \multirow{2}{*}{$\begin{array}{l}\text { Mean distance } \\
(\mathrm{m})^{1}\end{array}$} & \multirow{2}{*}{$\begin{array}{c}\text { Emergence }^{2} \\
\text { total }\left(n_{o}\right)\end{array}$} & \multirow{2}{*}{$\begin{array}{c}\text { Survivors } \\
\text { total }\end{array}$} & \multirow{2}{*}{$\begin{array}{c}\text { Outcrossing } \\
(\%)\end{array}$} & \multicolumn{2}{|c|}{$95 \%$ confidence interval $^{3}$} \\
\hline & & & & Lower & Upper \\
\hline 0.3 & 5764 & 36 & 0.62454 & 0.43688 & 0.86318 \\
\hline 1.3 & 6123 & 1 & 0.01633 & 0.00041 & 0.09107 \\
\hline 2.8 & 5406 & 0 & 0.00000 & 0.00000 & 0.08103 \\
\hline 4.3 & 5973 & 0 & 0.00000 & 0.00000 & 0.07333 \\
\hline 5.8 & 4805 & 0 & 0.00000 & 0.00000 & 0.09116 \\
\hline 7.3 & 5316 & 0 & 0.00000 & 0.00000 & 0.08239 \\
\hline 8.8 & 6141 & 0 & 0.00000 & 0.00000 & 0.07134 \\
\hline 10.3 & 4012 & 0 & 0.00000 & 0.00000 & 0.10916 \\
\hline 11.8 & 7079 & 0 & 0.00000 & 0.00000 & 0.06188 \\
\hline 13.3 & 7006 & 0 & 0.00000 & 0.00000 & 0.06253 \\
\hline 14.8 & 11312 & 0 & 0.00000 & 0.00000 & 0.03873 \\
\hline 16.3 & 13126 & 0 & 0.00000 & 0.00000 & 0.03338 \\
\hline 17.8 & 15390 & 0 & 0.00000 & 0.00000 & 0.02847 \\
\hline 19.3 & 16421 & 0 & 0.00000 & 0.00000 & 0.02668 \\
\hline 20.8 & 16962 & 0 & 0.00000 & 0.00000 & 0.02583 \\
\hline 22.3 & 13885 & 0 & 0.00000 & 0.00000 & 0.03155 \\
\hline 23.8 & 15501 & 1 & 0.00645 & 0.00016 & 0.03599 \\
\hline 25.3 & 15353 & 0 & 0.00000 & 0.00000 & 0.02854 \\
\hline 26.8 & 18490 & 1 & 0.00541 & 0.00014 & 0.03017 \\
\hline 28.3 & 22490 & 1 & 0.00445 & 0.00011 & 0.02481 \\
\hline 29.8 & 20510 & 0 & 0.00000 & 0.00000 & 0.02136 \\
\hline 31.3 & 20489 & 0 & 0.00000 & 0.00000 & 0.02139 \\
\hline 32.8 & 22506 & 1 & 0.00444 & 0.00011 & 0.02479 \\
\hline 34.3 & 28187 & 0 & 0.00000 & 0.00000 & 0.01554 \\
\hline 35.8 & 18177 & 0 & 0.00000 & 0.00000 & 0.02410 \\
\hline 37.3 & 31826 & 0 & 0.00000 & 0.00000 & 0.01377 \\
\hline 38.8 & 28791 & 1 & 0.00347 & 0.00009 & 0.01947 \\
\hline 40.3 & 25879 & 7 & 0.02705 & 0.01086 & 0.05563 \\
\hline 41.8 & 25894 & 0 & 0.00000 & 0.00000 & 0.01692 \\
\hline 43.3 & 26537 & 0 & 0.00000 & 0.00000 & 0.01651 \\
\hline 44.8 & 33958 & 3 & 0.00883 & 0.00182 & 0.02579 \\
\hline 46.3 & 45726 & 0 & 0.00000 & 0.00000 & 0.00958 \\
\hline 47.8 & 35213 & 1 & 0.00284 & 0.00007 & 0.01584 \\
\hline 49.3 & 41156 & 1 & 0.00243 & 0.00006 & 0.01356 \\
\hline Total & 621404 & 54 & - & - & - \\
\hline Mean & 18277 & 2 & - & - & - \\
\hline
\end{tabular}

\footnotetext{
${ }^{1}$ Mean distance was used in all analyses.

${ }^{2}$ The total and mean number of plants that emerged during the field screening with glufosinate for each distance sampled. Samples from the distances closest to the source for blocks $2,4,6$ and 8 were not harvested to avoid potential admixture with the transgenic source plot.

${ }^{3}$ The $95 \%$ confidence interval using a relationship between $\mathrm{F}$ and binomial distributions, with a correction for the lower interval value when the number of survivors was zero as outlined in Zar (1999), p. 528.
}

Outcrossing was detected at all distances for the Westwold site except from the 85239 seeds screened from the single non-transgenic plot $300 \mathrm{~m}$ from the transgenic pollen source (Tab. 2). From the power analysis, we would accept the null hypothesis that the frequency of transgenic seeds screened from this sample was equal to or greater than 0.00005 only $2.5 \%$ of the time.
Outcrossing was detected at very few distances at the Lethbridge site. All of the samples screened from the Lethbridge site at mean distances of 2.75 to $22.25 \mathrm{~m}$ from the transgenic pollen source did not contain a glufosinateresistant seed (Tab. 3). From the power analysis (Tab. 6) and the range of seeds screened from each distance, 4012 to 16962 , we would accept the null hypothesis $2.5 \%$ of 
Table 4. Parameter estimates and $\mathrm{O}_{50}$ and $\mathrm{O}_{95}$ values with their respective standard errors and confidence intervals from the regression analysis and equation 1,2 and $3^{1}$.

\begin{tabular}{lcccccc}
\hline \multirow{2}{*}{ Experiment } & Parameter $^{2}$ & Estimate $^{1}$ & Standard error & $\mathrm{Df}^{3}$ & Lower & Upper \\
\hline Chile & $a$ & 0.0025 & 0.0002 & 129 & 0.0020 & 0.0030 \\
& $b$ & 0.0757 & 0.0078 & 129 & 0.0603 & 0.0912 \\
& $\mathrm{O}_{50}$ & 9.1512 & 0.9421 & 129 & 7.2873 & 11.0151 \\
Westwold & $\mathrm{O}_{95}$ & 39.5507 & 4.0716 & 129 & 31.4950 & 47.6065 \\
& $a$ & 0.0168 & 0.0008 & 124 & 0.0152 & 0.0184 \\
& $b$ & 0.0607 & 0.0020 & 124 & 0.0566 & 0.0647 \\
& $\mathrm{O}_{50}$ & 11.4267 & 0.3838 & 124 & 10.6669 & 12.1864 \\
& $\mathrm{O}_{95}$ & 49.3852 & 1.6589 & 124 & 46.1018 & 52.6687 \\
& $a$ & 0.0011 & 0.0002 & 269 & 0.0007 & 0.0015 \\
& $b$ & 0.1126 & 0.0118 & 269 & 0.0893 & 0.1360 \\
& $\mathrm{O}_{50}$ & 6.1534 & 0.6469 & 269 & 4.8798 & 7.4270 \\
& $\mathrm{O}_{95}$ & 26.5946 & 2.7959 & 269 & 21.0901 & 32.0992 \\
\hline
\end{tabular}

${ }^{1}$ Estimates of the parameters for intercept $(a)$, slope $(b)$ and the estimates of the distance where outcrossing was reduced by 50 and 95\% (see text for regression equation). All predictions were significant $(P<0.0001)$.

${ }^{2}$ Parameters $a$ and $b$ were estimated from the regression analysis with equation 1 . The distance that outcrossing was reduced by 50 and $95 \%$ were estimated using equations 2 and 3 , respectively.

${ }^{3}$ Degrees of freedom.

Table 5. Outcrossing directionality: log-likelihood ratio test among blocks for each experiment.

\begin{tabular}{|c|c|c|c|c|c|c|c|c|c|}
\hline \multirow[t]{2}{*}{ Experiment } & \multirow[t]{2}{*}{ Block (s) } & \multirow[t]{2}{*}{ Direction $^{1}$} & \multicolumn{2}{|c|}{ Combined } & \multicolumn{2}{|c|}{ Partitioned $^{4}$} & \multicolumn{2}{|c|}{$X^{2}$ Value $^{5}$} & \multirow[t]{2}{*}{ Significance $^{6}$} \\
\hline & & & Value & $\mathrm{Df}^{7}$ & Value & $\mathrm{Df}^{7}$ & Value & $\mathrm{Df}^{7}$ & \\
\hline \multirow[t]{5}{*}{ Chile } & All & All & 693.2 & 16 & 571.3 & 2 & 121.9 & 14 & $* * * *$ \\
\hline & 1 vs. 5 & $\mathrm{~N}$ and $\mathrm{S}$ & 234.8 & 4 & 221.0 & 2 & 13.8 & 2 & $* * *$ \\
\hline & $2 v s .6$ & NE and SW & 128.9 & 4 & 125.4 & 2 & 3.5 & 2 & $n s$ \\
\hline & 3 vs. 7 & E and W & 143.5 & 4 & 95.0 & 2 & 48.5 & 2 & $* * * *$ \\
\hline & 4 vs. 8 & NW and SE & 145.8 & 4 & 129.9 & 2 & 15.9 & 2 & $* * * *$ \\
\hline \multirow{4}{*}{ Westwold } & All & All & 722.7 & 8 & 687.0 & 2 & 35.7 & 6 & $* * * *$ \\
\hline & 1 vs. 2 & $\mathrm{~N}$ and $\mathrm{S}^{2}$ & 301.8 & 4 & 297.5 & 2 & 4.3 & 2 & $n s$ \\
\hline & 2 vs. 3 & $\mathrm{~N}$ and $\mathrm{S}^{2}$ & 307.4 & 4 & 289.8 & 2 & 17.6 & 2 & $* * * *$ \\
\hline & 3 vs. 4 & $\mathrm{~N}$ and $\mathrm{S}^{2}$ & 398.5 & 4 & 389.5 & 2 & 9.0 & 2 & $*$ \\
\hline \multirow[t]{2}{*}{ Lethbridge } & All (less 1, 3 and 8$)^{8}$ & Subset of all & 312.4 & 10 & 149.2 & 2 & 163.2 & 8 & $* * * *$ \\
\hline & $2 v s .6$ & NE and SW & 21.3 & 4 & 19.9 & 2 & 1.4 & 2 & $n s$ \\
\hline
\end{tabular}

${ }^{1}$ Direction from the transgenic pollen source where ' $\mathrm{N}$ ' is north, ' $\mathrm{S}$ ' is south, 'W' is west and ' $\mathrm{E}$ ' is east.

${ }^{2}$ The Westwold blocks were in a North-South direction relative to the transgenic source plot, but are east and west of one another.

${ }^{3}$ The overall value is the -2 log-likelihood value calculated by SAS (2007) for the regression of the combined data set for the blocks being compared.

${ }^{4}$ The individual sum value is the sum of the -2 log-likelihood values calculated by SAS (2007) for each individual regression of the partitioned data sets for the blocks being compared.

${ }^{5}$ The chi-square value was calculated as twice the value of the log-likelihood ratio of the sum of the partial data sets and the combined data set.

${ }^{6}$ Significance is given for alpha $\leqslant 0.05,0.01,0.005$ and 0.001 corresponding to $*, * *, * * *$ and $* * * *$, respectively. When the value was not significant it was designated as $n s$.

${ }^{7}$ Degrees of freedom.

${ }^{8}$ At the Lethbridge site, the blocks 3 and 8 were excluded from the log-likelihood ratio test because the observed outcrossing frequency was zero at most distances for block 3 and all zeros for block 8 , and the program could not converge during the analysis. When block 1 was analyzed by itself, the program gave a warning and did not calculate the standard error and confidence intervals. This may have occurred because the only survivors observed were at the distal portion (farthest from the transgenic source plot). For this reason block 1 was excluded from the log-likelihood ratio tests. 
Gene flow from transgenic to conventional safflower

Table 6. Power analysis assuming a binomial distribution and using equation 2 (see text) to determine the minimum number of seeds to screen to detect at least one transgenic seed, for different levels of outcrossing and three alpha values.

\begin{tabular}{lcccc}
\hline \multirow{2}{*}{$\begin{array}{c}\text { Null hypothesis }{ }^{1} \\
\text { Frequency of } p(\mathrm{X})\end{array}$} & $0.05(5 \%)$ & $\begin{array}{c}\text { Alpha value }(\alpha) \\
\text { Minimum sample size }\left(n_{p}\right)^{2}\end{array}$ \\
\hline 0.01 & 299 & 368 & 459 & 528 \\
0.005 & 598 & 736 & 919 & 1058 \\
0.0025 & 1197 & 1474 & 1840 & 2117 \\
0.001 & 2995 & 3688 & 4603 & 5296 \\
0.0005 & 5990 & 7376 & 9209 & 10594 \\
0.00025 & 11982 & 14754 & 18419 & 21191 \\
0.0001 & 29956 & 36887 & 46050 & 52981 \\
0.00005 & 59914 & 73776 & 92102 & 105964 \\
0.000025 & 119828 & 147554 & 184205 & 211931 \\
0.00001 & 299572 & 368887 & 460515 & 529830 \\
0.000005 & 599145 & 737775 & 921032 & 1059661 \\
0.0000025 & 1198292 & 1475550 & 1842066 & 2119325 \\
\hline
\end{tabular}

\footnotetext{
${ }^{1}$ The theoretical value of outcrossing $(p)$.

${ }^{2}$ The minimum value of $n_{p}$ is the sample size required to detect one or more transgenic seeds given a theoretical frequency of transgenic seeds $(p)$ and different values of alpha. Values for minimum sample size were rounded upward to ensure they are within the bound set by the alpha value. The null hypothesis that the frequency is $X \geqslant p$ is rejected at a given percentage (alpha value) of the time, when no transgenic seeds were found in a sample size of $n_{p}$ or greater.
}

the time that the frequency of transgenic seeds in these samples would be equal to or greater than 0.001 and 0.00025 , respectively. The samples taken at a mean distance of $46.25 \mathrm{~m}$ in eight directions from the transgenic pollen source had 45726 seeds screened and no transgenic seeds were detected (Tab. 3). From the power analysis, we would accept the null hypothesis only $2.5 \%$ of the time that the frequency of transgenic seeds screened from this sample was equal to or greater than 0.0001 .

\section{DISCUSSION}

Safflower outcrossing among plants within 1 to $3 \mathrm{~m}$ from the transgenic pollen source at all three sites ranged from 0 to $1.7 \%$ (Fig. 1), similar to the outcrossing rates reported for high-oil-yielding safflower lines in the USA (1 to 5\%) (Claassen, 1950). Outcrossing declined steeply with distance, but was still detectable at very low frequencies at $49 \mathrm{~m}$ or more from the sources, ranging from 0.0024 to $0.03 \%$ at all three sites (Fig. 1). Outcrossing from transgenic safflower to non-transgenic plants was reduced more than $40 \%$ at $6 \mathrm{~m}$ and reduced 96$100 \%$ at $50 \mathrm{~m}$ (Fig. 1). The frequency of outcrossing from transgenic to non-transgenic Centennial safflower at distances greater than $3 \mathrm{~m}$ was ten times lower than that reported for safflower with different floral coloration in India (Deokar and Patil, 1976; Howard et al., 1915; Kadam and Patankar, 1942).

The power analysis, assuming a binomial distribution, allowed interpretation of samples with no transgenic seeds detected, which sometimes occurred after screening of large numbers of seeds. The ability to change the alpha value (type 1 error) and incorporate the various sample sizes from the screening process facilitated a robust estimate of the probable transgenic seed frequency in each sample.

The frequency of outcrossing was as heterogeneous among blocks (replicates) as it was among the sites. The regions where the outcrossing experiments were conducted all had predominantly westerly winds; however safflower flowered over a period of weeks and the wind direction varied considerably over that time. The results of the likelihood ratio test did not indicate greater outcrossing on the leeward side of any of the experiments. Because wind does not facilitate significant safflower outcrossing beyond $1.2 \mathrm{~m}$ (Claassen, 1950), it is likely that the heterogeneity in outcrossing pattern observed at all three outcrossing sites was due to non-random pollen movement by insects.

Outcrossing rates were influenced by site environment. Outcrossing differed among the three experiments (Tabs. 1 to 4), being the highest at Westwold and lowest at Lethbridge (Tabs. 2 and 3). The observed outcrossing frequency nearest the transgenic pollen source at Chile was more similar to Lethbridge than Westwold (Tabs. 1 to 4). Differences between sites could have been influenced by experimental design, which differed in the size of the transgenic pollen source plot and shape and distribution of the non-transgenic pollen recipient area. The Chilean and Lethbridge experiments had similar 
A

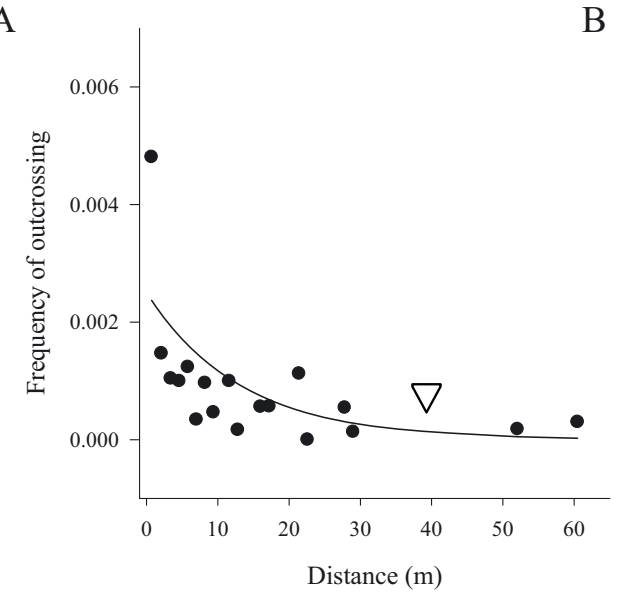

$\mathrm{C}$

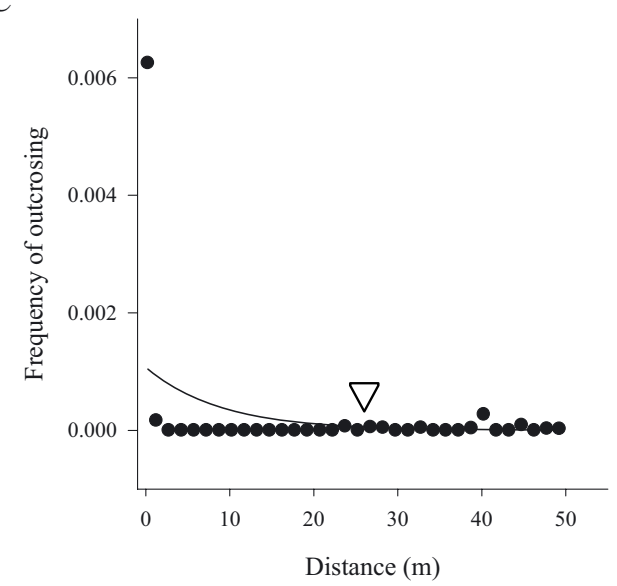

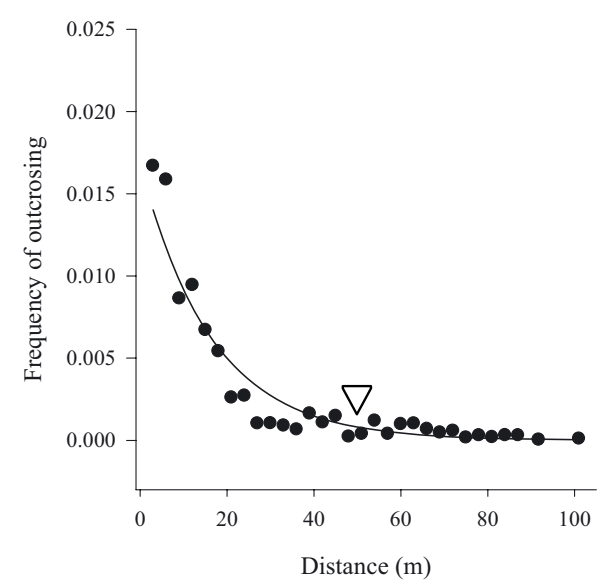

Figure 1. Frequency of outcrossing with increasing distance from the transgenic pollen source at (A) El Bosque Chile in 2002, (B) Westwold in 2002, and (C) Lethbridge in 2004. Arrows indicate $\mathrm{O}_{95}$ values (see Tab. 4 for regression equation and parameter estimates). Note the scale used for frequency of outcrossing differs among the graphs to prevent obscuring detail.

transgenic pollen source sizes and rates of outcrossing. The Westwold experiment had a pollen source three times greater in size than the others, and an outcrossing rate four times greater closest to the source, with a slower decline in outcrossing over distance as indicated by the $\mathrm{O}_{50}$ and $\mathrm{O}_{95}$ values (Tab. 4 and Fig. 1). The experiments at Chile and Westwold had barren zones (patches free of vegetation) between the transgenic source plot and the non-transgenic recipient plots, whereas the experiment at Lethbridge did not (Fig. 2). The lack of barren zones at Lethbridge may have reduced the rate of outcrossing observed relative to the other two sites. Barren zones between patches of insect-pollinated crop increased the distance of outcrossing in experiments ůconducted with Brassica campestris L. (Manasse, 1992) and Brassica napus L. (Morris et al., 1994; Reboud, 2003). The experimental designs would also provide different edge shapes for pollinators. Previous research has shown pollinators entering large monoculture fields may settle first at the edge and then move inward, increasing outcrossing at the field margin (Ramsay, 2005). In addition, studies have shown that pollinators deposit pollen from the first plant visited to the next few visited plants, creating a pattern of outcrossing referred to as a paternity shadow (Cresswell et al., 1995). If pollinators at the Chilean and Westwold sites followed these patterns of behavior, crossfertilization rates would depend on the direction they approached the safflower and where they would perceive the edge to be. At the Lethbridge site, the edge would have consistently been $50 \mathrm{~m}$ from the transgenic pollen source plot (Fig. 2).

Pollen movement may have been influenced by diverse-pollinating insects at the different sites. Butler et al. (1966) documented 40 species of non-parasitic bees 
A.

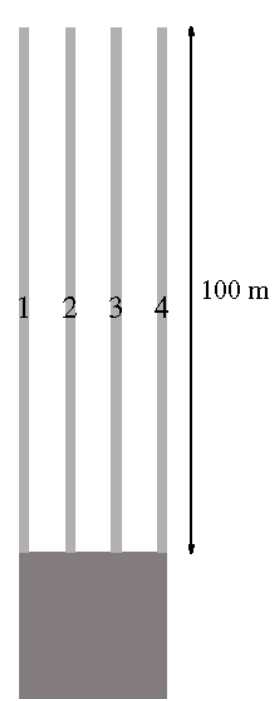

B.

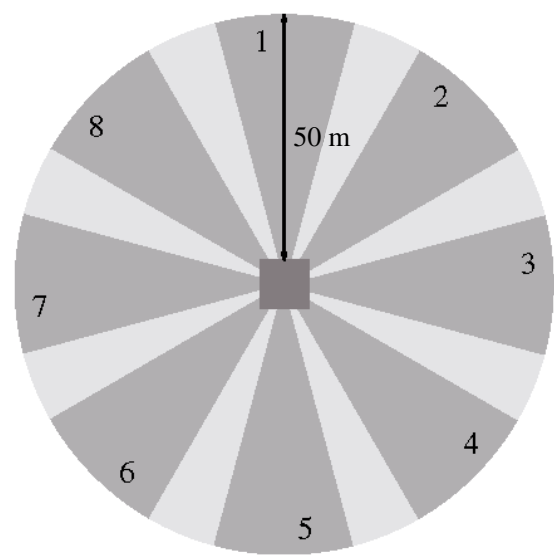

C.

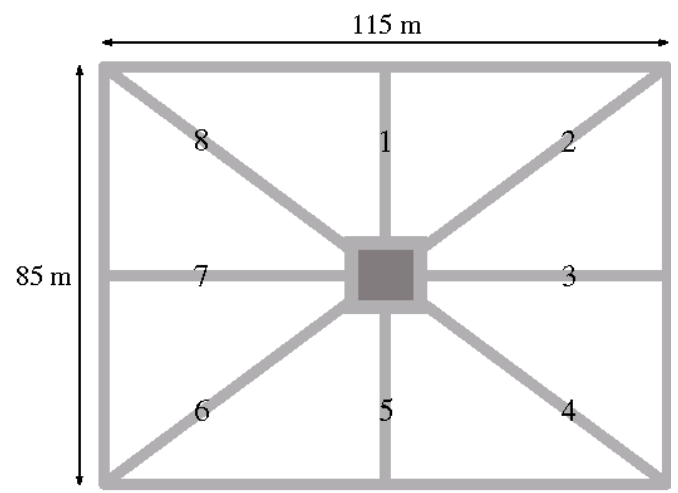

Figure 2. Experimental designs showing the spatial arrangement of the transgenic pollen source (darkest color), non-transgenic recipient plants (light and dark grey) and the area free of vegetation (white). (A) Westwold, British Columbia, (B) Lethbridge, Alberta, and (C) El Bosque, Chile. The light grey area was sampled and retained, whereas the dark grey area was not retained at harvest; numbers indicate blocks or replicates.

and their relative abundance on safflower experiments and commercial fields in Arizona. Native bees made up 10 to $15 \%$ of pollinators on safflower field experiments and 8 to $13 \%$ at the edge of commercial fields. Thus, pollinator diversity and movement patterns can vary greatly over short distances in similar agroecosystems.

The experiments presented here were designed to quantify pollen-mediated gene flow on a relatively small scale $(50$ to $100 \mathrm{~m}$ ), and do not predict maximum distances of pollen movement by pollinators or the distance required to isolate fields of transgenic safflower from outcrossing with commodity safflower. Long-distance bee foraging has been documented up to $11.2 \mathrm{~km}$ from the hive on sweet clover pollen (Ramsay, 2005), and one of 2000 marked bees was found foraging $7.1 \mathrm{~km}$ from the hive on safflower (Gary et al., 1977).

A trap crop consisting of non-transgenic plants surrounding transgenic safflower may minimize longdistance outcrossing by insects. Currently in Canada, trap crops are used to reduce pollen movement from transgenic oilseed rape (B. napus L.) field experiments (CFIA, 2006). The efficacy of a trap crop to reduce outcrossing has been documented for transgenic oilseed rape (Morris et al., 1994; Reboud, 2003; Staniland et al., 2000) and cotton (Gossypium hirsutum L.; Kareiva et al., 1994). The $\mathrm{O}_{95}$ for the safflower experiment with the highest outcrossing (Westwold) was $37.9 \mathrm{~m}$, suggesting a trap crop of this width around a transgenic safflower field could significantly reduce the risk of outcrossing to distant commodity safflower fields. Currently, seed growers maintain certified and foundation level safflower seed purity with an isolation distance of $400 \mathrm{~m}$ from other safflower varieties in the USA and Canada (Anonymous, 2007a, 2007b; CFIA, 2005). By using both a trap crop and isolation distance, safflower intended for PMF may be grown without compromising conventional safflower growers. However, in addition to information on outcrossing distance, threshold levels for adventitious presence of transgenes, based on risk for food and feed must be established. The current requirements for a confined crop are zero and would be difficult to maintain under field production conditions. The results presented here should aid industry and regulators to designate best management practices to mitigate pollen-mediated gene flow from transgenic safflower intended for PMF to commodity safflower.

Pollen-mediated gene flow has been quantified in detail in several crops using transgenic and marker genes including wheat (Triticum aestivum L.) (Gustafson et al., 2005; Hucl, 1996; Hucl and Matus-Cadiz, 2001; Matus-Cadiz et al., 2007), oilseed rape (B. napus) (Beckie et al., 2003; Damgaard and Kjellsson, 2005; Rieger et al., 2002; Weekes et al., 2005) and maize (Zea mays L.) (Goggi et al., 2006, 2007; Gustafson et al., 2006; Weekes et al., 2007) (reviewed in Beckie and Hall, 2008). Because of differences in research design and source plot size, studies are difficult to compare directly. Safflower and wheat appear to have similar outcrossing at a 10 meter distance, and both have lower pollen-mediated gene flow than oilseed rape and much lower levels of outcrossing than maize. We anticipate that, similar to other crops, 
seed mediated gene flow may be a more significant avenue for transgenic movement than via pollen.

\section{MATERIALS AND METHODS}

\section{Source of plant materials}

To quantify distance and direction of pollen-mediated gene flow from transgenic safflower intended for PMF to non-transgenic safflower under different environmental conditions, we conducted experiments at El Bosque, Chile and Westwold, BC in 2002 and Lethbridge, AB in 2004. Experiments were designed and implemented by different research groups and therefore varied at each site (Fig. 2). Non-transgenic seed cv. 'Centennial' safflower and cv. 'Centennial' safflower transformed using a construct encoding a seed-targeted protein and constitutive expressed phosphinothricin acetyltransferase (pat) were provided by SemBioSys Genetics Inc. (Calgary, Alberta, Canada). The seed lots were tested for crosscontamination between transgenic and non-transgenic safflower by screening with glufosinate in a greenhouse. Both seed lots were found to be true to type (described below under herbicide resistance of transgenic plants).

\section{Environmental biosafety compliance}

For all of the transgenic field experiments, confinement protocols were followed as outlined by the federal governments of Canada and Chile. These measures included appropriate isolation distances between transgenic and commodity safflower crops and other crop species, triple containment of seed to and from the site, cleaning and inspection of all equipment used at the sites, and frequent monitoring and control of safflower volunteers in the experimental sites and designated perimeters during the growing season and in post-harvest years.

\section{Outcrossing experimental design and implementation}

\section{El Bosque, Santiago, Chile}

Planting was conducted in the municipality of El Bosque, in the province of Santiago, Chile, near the Catholic University at Pirque $\left(32^{\circ} 47^{\prime} 49.18^{\prime \prime} \mathrm{S} ; 70^{\circ} 40^{\prime} 01.43^{\prime \prime} \mathrm{W}\right.$; elevation $732 \mathrm{~m}$ ), on September 14, 2002 in a wheel and spoke design (Fig. 2C). The transgenic $10 \times 11.2 \mathrm{~m}$ pollen source plot in the middle of the experiment consisted of 16 rows each $10 \mathrm{~m}$ in length. Four rows spaced $0.70 \mathrm{~m}$ apart of non-transgenic safflower were planted around the transgenic source plot for a total width of
$2.8 \mathrm{~m}$. Eight non-transgenic safflower blocks (replicates) with four rows of safflower $2.8 \mathrm{~m}$ wide were planted radially from the transgenic source plot. In addition, four rows of non-transgenic safflower were planted around the experiment in a rectangle of $115 \times 85 \mathrm{~m}$. Target seeding rates for both transgenic and non-transgenic cultivars were $30 \mathrm{~kg} \cdot \mathrm{ha}^{-1}$. The nearest glufosinate-resistant safflower field was $573 \mathrm{~m}$ away from the experiment, and the nearest non-GM safflower was $c a .1000 \mathrm{~m}$ away. Neighboring crops included an alfalfa (Medicago sativa L.) field $c a .200 \mathrm{~m}$ to the north-east, maize (Z. mays) $c a$. $200 \mathrm{~m}$ to the south-east, sunflower (Helianthus annuus L.) $c a .700 \mathrm{~m}$ to the south-west and sugar beets (Beta vulgaris L.) ca. $50 \mathrm{~m}$ to the north.

Seeds were harvested on March 15, 2003 by hand at 16 distance intervals from the source plot in each of the eight radial blocks. The first two samples nearest the pollen source were $2.8 \mathrm{~m}$ wide. Subsequent samples were $1.2 \mathrm{~m}$ wide. To reduce the amount of transgenic seed collected and transported to Canada for screening, areas between some samples were not harvested (Tab. 1). A total of 16 samples were harvested per radial block (replicate). In addition, samples were taken at the outer corners, the farthest distance from the transgenic source (Tab. 1).

\section{Westwold, British Columbia, Canada}

Planting was conducted in Westwold, BC $\left(50^{\circ} 28^{\prime}\right.$ $04.66^{\prime \prime} \mathrm{N} ; 119^{\circ} 45^{\prime} 09.26^{\prime \prime} \mathrm{W}$; elevation $616 \mathrm{~m}$ ), on May 17, 2002 in a comb design to maximize the distance of the pollen recipient plants to the source within available field dimensions (Fig. 2A). The transgenic pollen source plot was $30 \times 30 \mathrm{~m}$ and the non-transgenic safflower recipient plots were planted in four blocks extending South from the source plot. The recipient blocks were $107 \times 1.6 \mathrm{~m}$ in 16 rows. In addition, a plot of nontransgenic plants was $300 \mathrm{~m}$ from the experiment on the other side of an alfalfa field. Target seeding rates for transgenic and non-transgenic cultivars were $30 \mathrm{~kg}^{\mathrm{h}} \mathrm{ha}^{-1}$. The nearest glufosinate-resistant safflower was several kilometers away from the experiment. The farm site was surrounded by mixed boreal forest trees and its associated flora.

Seeds were harvested on October 16, 2002 with a Wintersteiger 2001 Elite research combine in an east/west direction with each sample consisting of a $1.2 \mathrm{~m}$ wide swath. Harvesting began furthest from the source plot to reduce cross-contamination of samples. Commingling of the non-transgenic samples closest to the transgenic pollen source at the Westwold site during harvest was suspected and these samples were removed from the analysis. The non-transgenic plot $300 \mathrm{~m}$ from the source was harvested separately after the harvester was cleaned and inspected. 


\section{Lethbridge, Alberta, Canada}

Seeds were planted in Lethbridge $\mathrm{AB}\left(49^{\circ} 41^{\prime} 51.91^{\prime \prime} \mathrm{N}\right.$; $112^{\circ} 46^{\prime}$ 24.82" W; elevation 909 m), on May 10, 2004 in a bulls-eye design. The transgenic source plot was $10 \times 9.9 \mathrm{~m}$ consisting of 55 rows located in the center of the experiment. The recipient non-transgenic safflower was planted $50 \mathrm{~m}$ around the transgenic pollen source plot with row spacing of $18 \mathrm{~cm}$. Target seeding rates for transgenic and non-transgenic cultivars were $30 \mathrm{~kg}^{-h^{-1}}{ }^{-}$. Once the safflower plants had bolted, the outside of the nontransgenic recipient plot was mowed into a circle with a $50 \mathrm{~m}$ perimeter around the transgenic pollen source. The closest transgenic and non-transgenic safflower was $>50 \mathrm{~km}$. The experiment was conducted on a research farm with a diversity of crop species grown, including barley (Hordeum vulgare L.) to the east, west and north for over $50 \mathrm{~m}$ and peas (Pisum sativum L.) to the south for over $50 \mathrm{~m}$.

Seeds were harvested on November 3, 2004. Eight wedges were removed ( $c a .1 / 3$ of the site area) between the blocks intended for harvest (Fig. 2B). The area removed between blocks had an outside arc distance of $14.4 \mathrm{~m}$. The remaining area comprised eight blocks with an outside arc distance of $28.8 \mathrm{~m}$ and an inside arc distance of $2.5 \mathrm{~m}$. Seeds were harvested in $1.2 \mathrm{~m}$ wide swaths from each block with a Wintersteiger 2001 Elite research combine and each swath was considered a plot. Harvesting began distal to the source and continued inward to reduce cross-contamination of samples.

\section{Herbicide resistance of transgenic plants}

A dose-response experiment with the herbicide glufosinate and homozygous transgenic and non-transgenic safflower plants was conducted in the greenhouse to determine a discriminating dose (Beckie et al., 2000). Experiments were conducted in the greenhouse at the University of Alberta, Edmonton, Alberta from 2004 to 2006 (data not shown).

Transgenic and non-transgenic seeds were planted in trays with six cells each (1 L per cell) containing soil-less vermiculite-peat mixture (Metro-Mix 290, The Scott's Company, 14111 Scottslawn Rd., Marysville, Ohio 43041). Twelve seeds per cell were planted and thinned to eight plants after emergence. Plants were exposed to natural light supplemented for $16 \mathrm{~h}$ by $400 \mathrm{~W}$ high pressure sodium, high intensity discharge bulbs and maintained at $21 / 18{ }^{\circ} \mathrm{C}$ day/night temperatures. Plants were watered as required and fertilized biweekly with complete 20-20-20 plus at a concentration of $200 \mathrm{ppm}$.

Glufosinate was applied to paired cells of transgenic and non-transgenic plants at $0,0.25,0.5,1,1.5$ and two times the recommended field rate of $400 \mathrm{~g}$ ai.ha ${ }^{-1}$ (grams active ingredient per hectare) (Ali, 2003). Each herbicide dose-response experiment had three replicates arranged in a randomized complete block design and was repeated three different times. Herbicide was applied when safflower had two to six true leaves using a custom built track sprayer with a Billericay Air Bubble Jet 110015 nozzle tip calibrated to deliver $100 \mathrm{~L}^{-\mathrm{ha}^{-1}}$ at $200 \mathrm{KPa}$. After herbicide application, trays were returned to the greenhouse and irrigated from above as required, commencing $24 \mathrm{~h}$ after application. Twenty-one days after herbicide application, plants were counted and cut at the soil surface, dried in paper bags at $60{ }^{\circ} \mathrm{C}$ for five days and dry weight measured.

Transgenic plants did not show signs of herbicide damage at rates of glufosinate as high as $800 \mathrm{~g}$ ai.ha ${ }^{-1}$ with a water volume of $100 \mathrm{~L} \cdot \mathrm{ha}^{-1}$ when the plants were at the two- to six-leaf stage, but occasionally a non-transgenic plant would survive. Further experiments were conducted with glufosinate applied at a rate of $800 \mathrm{~g}$ ai.ha ${ }^{-1}$ and an increased water volume of $200 \mathrm{~L} . h a^{-1}$ applied twice at a 4 - to 7 -day interval between applications. None of the 738 non-transgenic plants survived and all of the 738 transgenic plants showed no signs of herbicide injury.

Because pollen-mediated gene flow in the outcrossing experiments resulted in hemizygous seed, a second experiment was conducted to ensure the high rate of glufosinate used on the homozygous plants was an appropriate screening rate. Hand-pollination of homozygous transgenic 'Centennial' safflower plants with a non-transgenic 'S-317' safflower (and the reciprocal) was performed to generate hemizygous seeds. Seeds were planted in the greenhouse and screened as described above, except they were sprayed with glufosinate at $800 \mathrm{~g}$ ai.ha ${ }^{-1}$ with double the previous water volume $\left(200 \mathrm{~L}^{\mathrm{h} a^{-1}}\right)$. All of the plants survived without herbicide injury. The $F_{2}$ seeds harvested from the surviving hemizygous parents were planted and sprayed as above. Chi-square analysis of the $F_{2}$ plants with and without herbicide damage fit the predicted three to one ratio, confirming the parents were hemizygous and not the product of self-fertilization. Results were used to establish the herbicide rate and water volume to discriminate between transgenic and nontransgenic safflower in the field screening.

\section{Seed screening}

Seeds from all sites were cleaned and stored at $10{ }^{\circ} \mathrm{C}$ until field screening was performed. Seed from Chile was grown in 2004, and from the Westwold and Lethbridge sites in 2005, on land in Edmonton, Alberta never utilized for safflower cultivation. Seeding rates were adjusted for a target of 250 plants. $\mathrm{m}^{-2}$ based on seed germinability and kernel weight. An early fall frost at the Lethbridge 
site reduced seed viability, and on some occasions the maximum number of seeds that could be planted with the seeding equipment still did not provide the target plant density.

Prior to planting samples from the Chilean outcrossing experiments in 2004, the site was first tilled and glyphosate was applied at a rate of 810 grams acidequivalent per hectare $\left(\mathrm{g}\right.$ ae $\left.\cdot \mathrm{ha}^{-1}\right)$. Prior to planting samples from the Westwold and Lethbridge outcrossing experiments in 2005, the site was first tilled, packed with a spiral packer and glyphosate applied at $810 \mathrm{~g} \mathrm{ae} \cdot \mathrm{ha}^{-1}$. Seeds from the Westwold and Lethbridge sites were treated with Helix Xtra ${ }^{\circledR}$ (an insecticide-fungicide mixture of thiamethoxam, difenoconazole, mefenoxam, and fludioxonil) as recommended for oilseed rape to increase seedling emergence and survival. Previous germination experiments with Helix Xtra ${ }^{\circledR}$ have shown that it does not inhibit germination (unpublished data). Each plot was planted with a seed sample from an outcrossing experiment to a depth of 1.3 to $3.8 \mathrm{~cm}$ and consisted of six rows $7 \mathrm{~m}$ long spaced $20.3 \mathrm{~cm}$ apart with a $1 \mathrm{~m}$ alley between plots. Fertilizer (0-45-0) was placed with the seed at a rate of $1.8 \mathrm{~g} . \mathrm{m}^{-1}$ of row. Planting was performed with a reduced-disturbance Fabro air seeder equipped with Atom Jet double shoot openers. After seeding each plot, hoses and openers were checked to ensure all seeds were cleared. Several control plots of non-transgenic and transgenic safflower were randomly positioned among the outcrossing-sample plots to ensure the transgene was functional and verify herbicide efficacy and coverage.

When safflower seedlings were at the four- to sixleaf stage, plant number per plot was estimated based on three $0.25 \mathrm{~m}^{2}$ quadrats per plot. Following emergence counts, the seedlings were sprayed with glufosinate at $800 \mathrm{~g}$ ai.ha ${ }^{-1}$ using low drift Billericay Air Bubblejet nozzle tips that delivered a water volume of $200 \mathrm{~L} \cdot \mathrm{ha}^{-1}$, and the application repeated 4 to $7 \mathrm{~d}$ later. A week later, surviving safflower plants were counted. The frequency of outcrossing was calculated as the number of survivors following herbicide application as a proportion of the number of emerged seedlings.

To reduce the area of land required to screen samples, pairs of adjoining plots from the Westwold experiment were combined, thereby increasing the effective range of the distance from the transgenic pollen source (Tab. 2). In addition, to increase the number of seedlings screened and reduce the area of land dedicated to transgenic confinement, seed from the Westwold and Lethbridge experiments were planted, seedlings screened and removed in each plot three times over the growing season. For each round of screening, the surviving plants were counted and sampled, and then the field area was treated with $810 \mathrm{~g}$ ae.ha ${ }^{-1}$ glyphosate to kill all remaining transgenic safflower plants and any weeds. Seed from the same samples (outcrossing trial site and direction and distance from pollen source) were planted into the same plots to ensure any volunteers (late germinated seed) from prior screening tests did not confound the results.

\section{Molecular confirmation of field survivors}

A leaf from each plant surviving both applications of glufosinate in the field was harvested and frozen at $-20^{\circ} \mathrm{C}$. A subset of these samples were confirmed as transgenic using commercially available immunochromatographic lateral flow test strips (Strategic Diagnostic Inc. ${ }^{\circledR}$ ) and event-specific end-point PCR. Immunochromatography was carried out on $c a .0 .25 \mathrm{~cm}^{2}$ leaf tissue ground in the supplied kit buffer. After $5 \mathrm{~min}$, the lateral flow test strips were inserted and allowed to develop for another $5 \mathrm{~min}$.

For the PCR confirmation of field survivors, total genomic DNA was extracted from $c a .0 .25 \mathrm{~cm}^{2}$ leaf tissue using a CTAB-based protocol described by Doyle and Doyle (1987). Multiplex PCR was conducted with primers specific to a non-coding region of the safflower genome to indicate the reaction was working and primers specific to the herbicide resistance gene (pat) to confirm the presence of the transgene. The primers JCH1 (CAC ACT AAG CCA CTC CAA CC) and JCH4 (TTG ACA ACT CCA ATC CCT GC) were specific to the noncoding region and produced a $900 \mathrm{bp}$ product; the primers JCH5 (GAT CTG GGT AAC TGG TCT AAC TGG) and JCH6 (GTT GCA AGA TAG ATA CCC TTG GTT) were specific to pat and produced a 350-bp product. Each PCR was performed in $20 \mu \mathrm{L}$ volumes using 10 to $40 \mathrm{ng}$ of DNA template, $0.5 \mathrm{mM}$ of each primer, $500 \mathrm{mM} \mathrm{KCl}$, $100 \mathrm{mM}$ Tris- $\mathrm{HCl}$ (pH 8.4), $3.0 \mathrm{mM} \mathrm{MgCl}_{2}, 0.25 \mathrm{mM}$ each dNTP and 2 units of Taq DNA polymerase. Cycling conditions for amplification consisted of $95{ }^{\circ} \mathrm{C}$ for $10 \mathrm{~min}$, followed by 35 cycles of $95^{\circ} \mathrm{C}$ for $20 \mathrm{~s}, 59^{\circ} \mathrm{C}$ for $30 \mathrm{~s}$ and $72^{\circ} \mathrm{C}$ for $45 \mathrm{~s}$, followed by a final extension of $5 \mathrm{~min}$ at $72{ }^{\circ} \mathrm{C}$. Ten percent of each PCR reaction was loaded into $1.5 \%$ agarose gels; electrophoresis was conducted to separate the products and then visualized using ethidium bromide under UV light.

\section{Statistical analysis}

Experiments were analyzed separately (El Bosque, Westwold and Lethbridge) with outcrossing frequency $(f)$ calculated as the ratio of glufosinate survivor(s) to estimated total seedlings emerged $\left(n_{o}\right)$. A $95 \%$ confidence interval for the mean frequency of outcrossing at each distance was calculated, assuming a binomial distribution as described by Zar (1999), pp. 527-528 (Tabs. 1 to 3 ). This method is error-prone when a zero value is observed (no survivors in the 
sample), thus an alternative method was used when this occurred, as described by in Zar (1999), p. 528 (Tabs. 1 to 3$)$.

Mean frequency of outcrossing $(f)$ at each mean distance were subjected to regression analysis using a nonlinear regression mixed model (PROC NLMIXED) with Statistical Analysis Software (SAS, 2007). The binomial distribution ( binomial $\left(n_{o}, f\right)$ ) was employed to approximate the dependent variable. The data were fit to equation (1), an exponential decay function (Hanson et al., 2005):

$$
p=a \mathrm{e}^{-b d}
$$

where $p$ is the predicted outcrossing frequency, $a$ is the intercept, e is the natural $\log , b$ is a curve parameter (rate of decline), and $d$ is the mean distance (m) from the edge of the source plot. Model fit was evaluated by the significance of the parameter estimates and visual examination of the residual structure (Hanson et al., 2005). Several other equations were fitted to the data but the exponential decay provided the best fit to the data as assessed with AICC and visual inspection of residuals. The standard error and 95\% confidence intervals were calculated for each parameter estimate.

Using the regression estimation of equation 1, we estimated the distance where outcrossing was reduced by both 50 and $95 \%\left(\mathrm{O}_{50}\right.$ and $\left.\mathrm{O}_{95}\right)$ :

$$
\begin{aligned}
\mathrm{O}_{50} & =\frac{\ln 0.5^{*} a-\ln a}{-b} \\
\mathrm{O}_{95} & =\frac{\ln 0.01^{*} a-\ln a}{-b}
\end{aligned}
$$

where $a$ and $b$ are intercept and slope, respectively.

To test for heterogeneity of outcrossing among the blocks for each experiment, a log-likelihood ratio test or G-test using the chi-square distribution was conducted using the -2 log-likelihood score provided by SAS for regression analysis (as above) with outcrossing data sets partitioned by blocks compared to a data set containing all of the partitions (Zar, 1999, pp. 473-475) (Tab. 6).

In addition, a power analysis using binomial probabilities was conducted to determine sample size required to detect at least one transgenic seed for samples with different theoretical frequency (transgenic seed content) and three different alpha values (Zar, 1999, pp. 539-542) (Tab. 6). The minimum sample size to detect at least one transgenic seed at a given frequency and alpha value was derived from the following formula

$$
n_{p} \geq \frac{\ln \alpha}{\ln (1-p)}
$$

where $n_{p}$ is the minimum sample size required to detect one or more transgenic seeds with a set value of $\alpha$ for a sample containing a theoretical frequency of transgenic seeds $(p)$. The null hypothesis that the frequency is equal to or greater than $(p)$ could be rejected when zero transgenic seeds were found in a sample of seeds $\left(n_{p}\right)$ with a confidence value related to the type I error alpha value by $1-\alpha$.

\section{ACKNOWLEDGEMENTS}

This study was funded from the University of Alberta, Natural Sciences Engineering Research Council of Canada (NSERC), New Initiatives Fund Alberta Agriculture and Food (AAF), and SemBioSys Genetics Inc. We acknowledge the technical support from Lisa Raatz, Debby Topinka, and Greg Iwaasa. Technical, agronomic, and scientific inputs were provided from several people with Alberta Agriculture and Food. Brad D. Hanson and Dr. Carol A. Mallory-Smith provided statistical advice and SAS code used for the regression analysis. We would like to extend our gratitude to Brian Otto, Jerry Kubik Jr., Dan Stryker and their families for use of their land and the time they provided during interviews, planning of experiments and helping to maintain plot areas.

Received April 8, 2008; accepted December 2nd, 2008.

\section{REFERENCES}

Ali S, ed (2003) Crop Protection. Alberta Agriculture, Food and Rural Development, Alberta, Canada

Anonymous (2007a) Canadian Seed Growers' Association: Crop Certification Regulations (Circular 6). Accessed electronically, 10 November 2007, http://www.seedgrowers.ca/ cropcertification/circular.asp

Anonymous (2007b) Utah Crop Improvement Association. Accessed electronically, 29 July 2007, http://utahcrop.org/ Requirements_and_Standards/Requirements_and_Standards. html

Beckie HJ, Hall LM (2008) Simple to complex: Modelling crop pollen-mediated gene flow. Plant Sci. 175: 615-628

Beckie HJ, Heap IM, Smeda RJ, Hall LM (2000) Screening for herbicide resistance in weeds. Weed Technol. 14: 428-445

Beckie HJ, Warwick SI, Nair H, Seguin-Swartz GS (2003) Gene flow in commercial fields of herbicide-resistant canola (Brassica napus). Ecol. Appl. 13: 1276-1294

Butler GD, Jr, Werner FG, Levin DA (1966) Native bees associated with safflower in South Central Arizona. J. Kan. Entomol. Soc. 39: 434-436

[CFIA] Canadian Food Inspection Agency - Plant Products Directorate (2005) Special Crops and New Crop Inspection Procedures. Accessed electronically, 10 November 2007, http://www.inspection.gc.ca/english/plaveg/seesem/man/ swi-spece.shtml 
[CFIA] Canadian Food Inspection Agency (2006) Specific terms and conditions to conduct field trials with PNT. Accessed electronically, 6 April 2007, http://www.inspection. gc.ca/english/plaveg/bio/dt/term/2006/2006e.shtml

Claassen CE (1950) Natural and controlled crossing in safflower, Carthamus tinctorius L. Agron. J. 42: 301-304

Cresswell JE, Bassom AP, Bell SA, Collins SJ, Kelly TB (1995) Predicted pollen dispersal by honey-bees and three species of bumble-bees foraging on oil-seed rape: A comparison of three models. Funct. Ecol. 9: 829-841

Damgaard C, Kjellsson G (2005) Gene flow of oilseed rape (Brassica napus) according to isolation distance and buffer zone. Agric. Ecosyst. Environ. 108: 291-301

Deokar AB, Patil FB (1976) Vicinism in safflower. Journal of Maharashtra Agricultural Universities 1: 232-234

Doyle JJ, Doyle JL (1987) A rapid DNA isolation procedure from small quantities of fresh leaf tissues. Phytochem. Bull. 19: $11-15$

Eastham K, Sweet J (2002) Genetically modified organisms (GMOs): The significance of gene flow through pollen transfer. European Environment Agency, Copenhagen, UK

Ellstrand N (2003) Going to "great lengths" to prevent the escape of genes that produce specialty chemicals. Plant Physiol. 132: $1770-1774$

Fritz S, Lukaszewski A (1989) Pollen longevity in wheat, rye and triticale. Plant Breed. 102: 31-34

Gary NE, Witherell PC, Lorenzen K, Marston JM (1977) The interfield distribution of honey bees foraging on carrots, onions, and safflower. Environ. Entomol. 5: 637-640

Goggi AS, Caragea P, Lopez-Sanchez H, Westgate M, Arritt R, Clark C (2006) Statistical analysis of outcrossing between adjacent maize grain production fields. Field Crops Res. 99: 147-157

Goggi AS, Lopez-Sanchez H, Caragea P, Westgate M, Arritt R, Clark CA (2007) Gene flow in maize fields with different local pollen densities. Int. J. Biometeorol. 51: 493-503

Gustafson DI, Horak MJ, Rempel CB, Metz SG, Gigax DR, Hucl P (2005) An empirical model for pollen-mediated gene flow in wheat. Crop Sci. 45: 1286-1294

Gustafson DI, Rosenbaum EW, Soteres JK, Remund KM, Brants IO, Horak MJ (2006) Empirical modeling of genetically modified maize grain production practices to achieve European Union labeling thresholds. Crop Sci. 46: 21332140

Hanson BD, Mallory-Smith CA, Shafii B, Thill DC, Zemetra RS (2005) Pollen-mediated gene flow from blue aleurone wheat to other wheat cultivars. Crop Sci. 45: 1610-1617

Howard A, Howard GLC, Khan AR (1915) Studies in Indian oil-seeds. Memoirs of the Department of Agriculture in India 7: 237-272

Hoyle M, Hayter K, Cresswell JE (2007) Effect of pollinator abundance on self-fertilization and gene flow: Application to GM canola. Ecol. Appl. 17: 2123-2135

Hucl P (1996) Out-crossing rates for 10 Canadian spring wheat cultivars. Can. J. Plant Sci. 76: 423-427

Hucl P, Matus-Cadiz M (2001) Isolation distances for minimizing out-crossing in spring wheat. Crop Sci. 41: 1348-1351
Kadam BS, Patankar VK (1942) Natural cross-pollination in safflower. Indian J. Genetics Pl. Breeding 2: 69-70

Kareiva P, Morris W, Jacobi CM (1994) Studying and managing the risk of cross fertilization between transgenic crops and wild relatives. Mol. Ecol. 3: 15-21

Levin DA, Kerster HW (1974) Gene flow in seed plants. Evol. Biol. 7: 139-220

Luna SV, Figueroa JM, Baltazar BM, Gomez RL, Townsend R, Schoper JB (2001) Maize pollen longevity and distance isolation requirements for effective pollen control. Crop Sci. 41: $1551-1557$

Manasse RS (1992) Ecological risks of transgenic plants: Effects of spatial dispersion on gene flow. Ecol. Appl. 2: 431438

Matus-Cadiz MA, Hucl P, Dupuis B (2007) Pollen-mediated gene flow in wheat at the commercial scale. Crop Sci. 47: 573-581

Messeguer J (2003) Gene flow assessment in transgenic plants. Plant Cell Tissue Organ Cult. 73: 201-212

Morris W, Kareiva P, Raymer P (1994) Do barren zones and pollen traps reduce gene escape from transgenic crops? Ecol. Appl. 4: 157-165

Muendel HH, Blackshaw RE, Byers RJ, Huang HC, Keon JR, Kubik J, McKenzie R, Otto B, Roth B, Stanford K (2004) Safflower Production on the Canadian Prairies: revisited in 2004. Agriculture and Agri-Food Canada, Lethbridge Research Centre, Lethbridge, Alberta

Ramsay G (2005) Pollen dispersal vectored by wind or insects. In Poppy, MJ Wilkinson, eds, Gene flow from GM plants, Blackwell Publishing, Ames, Iowa, USA, pp 43-77

Reboud X (2003) Effect of a gap on gene flow between otherwise adjacent transgenic Brassica napus crops. Theor. Appl. Genet. 106: 1048-1058

Rieger MA, Lamond M, Preston C, Powles SB, Roush RT (2002) Pollen-mediated movement of herbicide resistance between commercial canola fields. Science (Wash.) 296: 23862388

Rognli OA, Nilsson NO, Nurminiemi M (2000) Effects of distance and pollen competition on gene flow in the windpollinated grass Festuca pratensis Huds. Heredity 85: 550560

[SAS] Statistical Analysis Systems (2007) SAS/STAT User's Guide: Statistics. SAS Institute Inc., Cary NC

Staniland BK, McVetty PBE, Friesen LF, Yarrow S, Freyssinet G, Freyssinet M (2000) Effectiveness of border areas in confining the spread of transgenic Brassica napus pollen. Can. J. Plant Sci. 80: 521-526

Weekes R, Deppe C, Allnutt T, Boffey C, Morgan D, Morgan S, Bilton M, Daniels R, Henry C (2005) Crop-to-crop gene flow using farm scale sites of oilseed rape (Brassica napus) in the UK. Transgenic Res. 14: 749-759

Weekes R, Allnutt T, Boffey C, Morgan S, Bilton M, Daniels R, Henry C (2007) A study of crop-to-crop gene flow using farm scale sites of fodder maize (Zea mays L.) in the UK. Transgenic Res. 16: 203-211

Zar JH (1999) Biostatistical Analysis. Prentice-Hall, Inc., Upper Saddle River, New Jersey, USA, pp 473-475, 527-528, 539-542 